\title{
PENSAMENTO COMPUTACIONAL NA MATEMÁTICA DO ENSINO MÉDIO: UMA PROPOSTA PEDAGÓGICA PARA O ESTUDO DE FUNÇÃO
}

\section{Computational Thinking in High School Mathematics: A Pedagogical Proposal for the Study of Function}

\author{
Lívia Ladeira Gomes ${ }^{1}$ \\ Silvia Cristina Freitas Batista ${ }^{2}$ \\ Gilmara Teixeira Barcelos Peixoto ${ }^{3}$
}

\begin{abstract}
Resumo: Função é um tema relevante para o estudo de outros conteúdos matemáticos, assim como para o desenvolvimento de diversas áreas do conhecimento, porém os estudantes nem sempre o compreendem satisfatoriamente. Nesse contexto, promoveu-se uma pesquisa que investigou como uma proposta pedagógica baseada nos princípios do Pensamento Computacional e na Teoria da Aprendizagem Significativa pode contribuir para o estudo de Função no Ensino Médio. Neste artigo, tem-se por objetivo apresentar a análise dos resultados da experimentação dessa proposta, realizada com alunos da $1^{a}$ série do Ensino Médio de uma Instituição Federal de Educação. Resumidamente, Pensamento Computacional é a aplicação de fundamentos da computação para planejamento e execução de estratégias, tendo em vista a solução de problemas. No estudo realizado, essas estratégias foram desenvolvidas com e sem o apoio de tecnologias digitais. A pesquisa delineou-se como qualitativa, do tipo Intervenção Pedagógica, ocorrendo em formato de curso extracurricular, realizado remotamente, devido à pandemia de COVID-19, com oito encontros síncronos. Os instrumentos de coleta de dados foram observação, questionários (inicial e final) e atividades (de sondagem conceitual, da terceira seção da apostila elaborada e final). Uma parte da análise de dados foi promovida com base no aporte teórico e a outra ocorreu por meio da metodologia Análise de Erros. Os resultados indicaram contribuições do uso do Pensamento Computacional de forma integrada ao currículo de Matemática, como proposto na Base Nacional Comum Curricular. Foram observados indícios de aprendizagem significativa em tópicos abordados e também melhorias na capacidade de resolução de problemas por parte dos alunos.
\end{abstract}

Palavras-chave: Pensamento Computacional. Teoria da Aprendizagem Significativa. Estudo de Função.

\footnotetext{
${ }^{1}$ Mestra em Ensino e suas Tecnologias pelo Instituto Federal de Educação, Ciência e Tecnologia Fluminense (2021). Técnica em Assuntos Educacionais no Instituto Federal de Educação, Ciência e Tecnologia Fluminense. Orcid: https://orcid.org/0000-0001-5644-1620. Contato: livia.gomes@iff.edu.br.

${ }^{2}$ Doutora em Informática na Educação pela Universidade Federal do Rio Grande do Sul (2011). Professora do Mestrado Profissional em Ensino e suas Tecnologias no Instituto Federal de Educação, Ciência e Tecnologia Fluminense. Orcid: https://orcid.org/0000-0003-4692-9408. Contato: silviac@iff.edu.br.

${ }^{3}$ Doutora em Informática na Educação pela Universidade Federal do Rio Grande do Sul (2011). Professora do Mestrado Profissional em Ensino e suas Tecnologias no Instituto Federal de Educação, Ciência e Tecnologia Fluminense. Orcid: https://orcid.org/0000-0002-5088-6511. Contato: gilmarab@iff.edu.br.
} 
Abstract: Function is a relevant topic for the study of other mathematical contents as well as for the development of different areas of knowledge, however students do not always understand it appropriately. In this context, a research that investigated how a pedagogical proposal based on the principles of Computational Thinking and on the Meaningful Learning Theory can contribute to the study of function in High School was promoted. This article aims to present the analysis of the results of the experimentation of this proposal, carried out with 1st. High School series of a Federal Educational Institution. Shortly, Computational Thinking is the application of computing fundamentals to planning and executing of strategies, in order to solve problems. In the conducted study, these strategies were developed with and without the support of digital technologies. The research was outlined as a qualitative Pedagogical Intervention type, taking place as an extracurricular course, implemented remotely, due to the COVID-19 pandemic, with eight synchronous meetings. The data collection instruments were observation, questionnaires (initial and final) and activities (conceptual survey, from the third section of the handout, and final). One part of the data analysis was fostered based on the theoretical contribution and the other part took place through the Error Analysis methodology. The results indicated contributions from the use of Computational Thinking in an integrated way to the Mathematics curriculum, as proposed in the National Common Curricular Base. There was clear evidence of meaningful learning in the covered topics and also improvements in the students' problem-solving ability.

Keywords: Computational Thinking. Meaningful Learning. Function Study.

\section{Introdução}

Diante das demandas da sociedade contemporânea, o conhecimento matemático tornase necessário a todos os alunos da Educação Básica (BRASIL, 2018). Dentre os conteúdos estudados, destaca-se o tema Função em razão das conexões que promove com outros conceitos da Matemática e de diversas outras áreas (LOPES, 2003; SANTOS; BARBOSA, 2016).

Apesar dessa importância, diversos trabalhos apontam que o estudo de Função ainda representa uma dificuldade na vida escolar do aluno (CURY; CASSOL, 2004; NASSER; SOUZA; TORRACA, 2012) e, segundo Lima (2008), é possível associar essas dificuldades à não ocorrência de uma aprendizagem significativa desse conteúdo matemático. Nesse sentido, a Teoria da Aprendizagem Significativa (TAS), cunhada por David Ausubel (2003), pode trazer contribuições.

Essencialmente, três condições devem ser satisfeitas para que ocorra uma aprendizagem significativa conforme a TAS: i) a existência de um material potencialmente significativo; ii) a predisposição do aluno para aprender; e iii) a existência de conhecimentos prévios relevantes (AUSUBEL, 2003; MOREIRA, 2012). Segundo Almeida, Costa e Lopes (2017), as tecnologias digitais (TD) podem favorecer essas condições.

No Brasil, com a homologação da Base Nacional Comum Curricular (BNCC) para toda a Educação Básica (BRASIL, 2018), as TD passaram a ter maior enfoque no cenário educacional. O objetivo é que os estudantes não só consumam tecnologias, mas também as utilizem para implementarem soluções, criarem modelos, refletirem criticamente diante de situações propostas, entre outros (BRASIL, 2018).

Para tanto, na BNCC (BRASIL, 2018), três eixos estruturantes são propostos para nortear as atividades frente às habilidades a serem desenvolvidas: Mundo Digital, Cultura Digital e Pensamento Computacional. Almeida e Valente (2019) apontam que o Pensamento 
Computacional, em especial, ainda se encontra em processo de implementação como eixo transversal ao currículo em alguns países, dentre eles o Brasil.

No âmbito deste trabalho, define-se Pensamento Computacional como "[...] o processo de pensamento envolvido na formulação de um problema e na expressão de sua(s) solução(ões) de tal forma que um computador - humano ou máquina - possa efetivamente executar." (WING, 2017, p. 8, tradução nossa).

Trabalhos como o de Costa (2017) e de Mestre (2017) apresentam uma relação entre o Pensamento Computacional e a Matemática, principalmente no que diz respeito à resolução de problemas. Isso favorece propostas para estudo de conteúdos matemáticos, como Função, que associam a resolução de problemas sobre o tema ao desenvolvimento do Pensamento Computacional, como sugere a BNCC (BRASIL, 2018).

Adicionalmente, fazer uso tanto de atividades plugadas, quanto de atividades desplugadas pode promover um ambiente adequado à aprendizagem significativa de Função, conforme as condições estabelecidas por Ausubel (2003). Essas atividades, que são, respectivamente, aquelas mediadas pelo uso de TD e as realizadas sem esses recursos (BRACKMANN, 2017) podem ser configuradas como materiais potencialmente significativos e, também, influenciar a disposição do aluno para aprender.

No que diz respeito ao desenvolvimento do Pensamento Computacional por meio de atividades plugadas, diversas ferramentas digitais têm sido utilizadas, tais como Code.org, GeoGebra, LightBot, Scratch, entre outras. Dentre essas, adotou-se, neste trabalho, o GeoGebra, uma ferramenta pedagógica gratuita disponível em diferentes plataformas (DOMINGUES; STURION; CARVALHO, 2019) e que pode ser utilizada em diferentes disciplinas. Além disso, quando usado adequadamente, o GeoGebra tende a promover conexão entre novas informações e as já aprendidas, assim como facilitar o uso de diferentes estratégias para a resolução de atividades e problemas (CRUZ, 2019).

Diante do exposto, foi realizada uma pesquisa de mestrado ${ }^{4}$ que buscou investigar como uma proposta pedagógica baseada nos princípios do Pensamento Computacional e na Teoria da Aprendizagem Significativa pode contribuir para o estudo de Função no Ensino Médio. Essa proposta é composta por um conjunto de atividades didáticas e de orientações teóricas e práticas, tendo em vista promover o estudo de tópicos iniciais de Função. Neste artigo, apresenta-se um recorte da dissertação elaborada (GOMES, 2021) com o objetivo de apresentar a análise dos resultados obtidos na experimentação da proposta.

A pesquisa foi caracterizada como qualitativa, do tipo Intervenção Pedagógica. A experimentação da proposta ocorreu em forma de um Curso extracurricular, chamado Estudo Introdutório de Função, realizado, em 2020, de forma remota, devido à pandemia da COVID19. O curso foi promovido com alunos da $1^{\text {a }}$ série do Ensino Médio de uma Instituição Federal de Educação.

Os dados foram coletados por meio de observação, dois questionários (inicial e final), e três atividades: de sondagem conceitual, da terceira seção da apostila "Introdução de Função", elaborada para a pesquisa, e a final. A referida apostila é composta por três seções, sendo as duas primeiras, respectivamente, sobre resolução de problemas e conteúdo de Função. A análise desses dados foi promovida com base no aporte teórico adotado e na metodologia Análise de Erros. Segundo Cury (2007), essa metodologia faz uma adaptação da Análise de Conteúdo de

\footnotetext{
${ }^{4}$ Pesquisa desenvolvida pela primeira autora deste artigo, sob orientação das demais autoras. Mestrado Profissional em Ensino e suas Tecnologias - Instituto Federal Fluminense.
} 
Bardin (1977), adotando como documentos de análise as respostas de alunos a problemas matemáticos.

Diante do exposto, este trabalho encontra-se estruturado em quatro seções, além desta Introdução. Na seção 2, discutem-se aspectos teóricos que buscam fundamentar a integração, promovida no estudo, entre os seguintes temas: estudo de Função, Pensamento Computacional e a TAS. Além disso, nessa mesma seção, abordam-se os trabalhos relacionados à proposta realizada. Na seção 3, são descritos os procedimentos metodológicos adotados. A seção 4 trata dos resultados obtidos na experimentação com o público-alvo. Por fim, na seção 5, são tecidas algumas considerações finais sobre o trabalho realizado.

\section{Aporte teórico}

Caraça (1951) apresenta o conceito de Função como unificador de dois grandes campos da Matemática: o geométrico e o analítico. Daí sua grande importância dentro da própria Matemática, pelas correspondências que possibilita. Tal importância também é reconhecida por Eves (2011), que, além de apresentar o conceito de Função como unificador, relaciona a sua compreensão a uma boa formação matemática. Também se pode observar uma intrínseca relação entre o conceito de Função e as ciências naturais, como a Física e a Química, e, de fato, observam-se muitas aplicações nessas áreas, a exemplo do estudo de movimentos na Física ou de concentrações na Química (LEMOS, 2013).

Apesar dessas constatações, Sousa e Moura (2019) apontam que alunos de Ensino Médio não compreendem esse conceito matemático, como se torna evidente nas aulas de Física ou de Química, quando as funções deixam de ser representadas por $f(x)$ e os alunos não conseguem identificar o conteúdo em foco como uma função. Outras dificuldades são relacionadas aos conjuntos domínio e imagem, à realização de análises gráficas e à resolução de problemas sobre a temática (ALEXANDRE; SANTOS, 2009), e também à construção gráfica (JUSTULIN; PEREIRA; FERREIRA, 2019). Nesse contexto, a pesquisa buscou contemplar algumas das dificuldades encontradas na literatura, por meio de atividades que compuseram a proposta pedagógica.

No âmbito deste trabalho, define-se Pensamento Computacional segundo Wing (2017), conforme destacado na Introdução. Na literatura, são encontradas outras definições, porém frisa-se que, independente da definição adotada, o Pensamento Computacional não pode ser confundido com a manipulação de tecnologias digitais e nem com uma forma de pensar mecânica, que restringe a capacidade de pensamento humano (BRACKMANN, 2017).

Wing (2006, p. 33, tradução nossa) também afirma que "[...] para ler, escrever e calcular, devemos adicionar o Pensamento Computacional à capacidade analítica de cada criança.”. Papert, em 1960, já investigava o uso da programação pela linguagem Logo para fins educacionais, apesar de não ter citado o termo Pensamento Computacional propriamente dito (VALENTE, 2016). Papert (1971) argumentou que a computação pode ter um grande impacto na educação por permitir a concretização de conceitos de diversas áreas, uma vez que possibilita à criança a capacidade de articular o trabalho de sua própria mente. Dessa forma, pode-se considerar que Papert e Wing foram pioneiros na discussão da inserção do Pensamento Computacional no cenário escolar (CONFORTO et al., 2018).

A partir disso, diversos países vêm implementando o Pensamento Computacional em seus currículos da Educação Básica (VALENTE, 2016). Três formas de implementação podem ser identificadas: i) atividades de ciência da computação, que se subdividem em atividade de programação de forma complementar ao currículo e disciplinas no currículo sobre letramento 
digital; ii) Pensamento Computacional como uma disciplina curricular; iii) Pensamento Computacional como uma atividade transversal ao currículo (VALENTE, 2016). No Brasil, com a homologação da BNCC (BRASIL, 2018), o Pensamento Computacional apresenta-se conforme o último item listado.

Segundo Brackmann (2017), os quatro princípios relacionados ao desenvolvimento do Pensamento Computacional, como citado na Introdução, são: i) Decomposição: envolve identificar um problema complexo e subdividi-lo em partes menores, mais fáceis de gerenciar; ii) Reconhecimento de Padrões: análise mais profunda de cada problema menor, buscando-se por problemas semelhantes que já foram resolvidos anteriormente; iii) Abstração: filtragem das informações que são relevantes para a resolução; iv) Algoritmo: passos, algoritmos, para resolver cada um dos problemas desmembrados.

Pode-se observar, principalmente pelo princípio Reconhecimento de Padrões, uma valorização dos conhecimentos que o aluno já detém. A busca pela promoção de uma aprendizagem significativa, conforme propõe a TAS de Ausubel, apresenta-se favorável ao desenvolvimento do Pensamento Computacional, uma vez que essa "[...] se caracteriza pela interação entre conhecimentos prévios e conhecimentos novos [...]" (MOREIRA, 2012, p. 2).

É importante esclarecer que, embora muitas vezes confundida como sinônimo de uma aprendizagem com significado, com aplicações para a vida, a aprendizagem significativa, conforme Ausubel (2003), é apresentada como o oposto de uma aprendizagem mecânica, tida por ele como memorística (MOREIRA, 2012). Trazendo uma definição, aprendizagem significativa, segundo a TAS proposta por David Ausubel em 1968, "[...] é aquela em que ideias expressas simbolicamente interagem de maneira substantiva e não-arbitrária com aquilo que o aprendiz já sabe." (MOREIRA, 2012, p. 2).

Interagir de forma substantiva equivale a estabelecer uma conexão não literal, ou seja, trata-se de uma interação que tem um significado lógico (AUSUBEL, 2003). Já a interação não arbitrária pode ser entendida como uma interação plausível, que não seja aleatória ou que não se dê a partir de qualquer conhecimento prévio, mas sim de conhecimentos especificamente relevantes (AUSUBEL, 2003; MOREIRA, 2012).

Em suma, pode-se dizer que a aprendizagem significativa é aquela que ocorre quando o aluno utiliza conhecimentos relevantes que já detém para construir novos conhecimentos. A esses conhecimentos prévios do estudante, Ausubel (2003) denomina subsunçores ou ideias âncora. Moreira (2012) complementa dizendo que esses subsunçores podem ter maior ou menor estabilidade na estrutura cognitiva do aluno, porém, como a assimilação ocorre na interação desses com os novos conhecimentos, os próprios subsunçores adquirem novos significados no processo, tornando-se, assim, mais estáveis.

De acordo com as discussões feitas por Moreira (2012), em consonância com a teoria de Ausubel (2003), para que a aprendizagem significativa ocorra, há três condições que devem ser satisfeitas: i) existência de um material potencialmente significativo ${ }^{5}$, que tenha um sentido lógico; ii) predisposição do aluno para aprender; iii) o aprendiz deve possuir os subsunçores relevantes com os quais o novo conceito possa ser relacionado.

Quando o aluno não possui os subsunçores necessários, Ausubel (2003) propõe o uso de organizadores prévios. Segundo Moreira (2012), esses organizadores são recursos instrucionais, como uma aula, um problema, uma leitura introdutória, que sejam mais genéricos

\footnotetext{
${ }^{5}$ Segundo Moreira (2012), material potencialmente significativo é aquele que pode ser relacionado de forma substantiva e não-arbitrária com a estrutura cognitiva do aluno.
} 

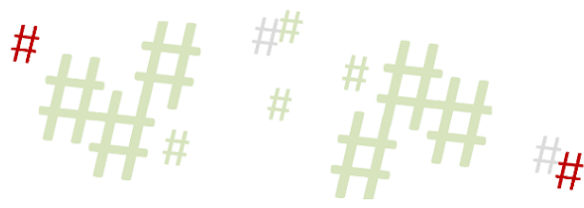

que o material de aprendizagem. Para o autor, o organizador prévio pode ser expositivo ou comparativo. É expositivo quando o material não é familiar ao aluno e, nesse caso, funciona como ponte entre o que o aluno deveria saber e o que já sabe. É comparativo quando o material é relativamente familiar para o aluno e, nesse caso, ajuda a integrar novos conhecimentos na estrutura cognitiva dos estudantes assim como a diferenciá-los dos já existentes nessa estrutura, mas que podem ser confundidos.

Segundo Cursino (2017), o uso de tecnologias digitais traz contribuições à aprendizagem significativa. Assim, considerou-se, como temática central da pesquisa, a associação do Pensamento Computacional, por meio das atividades plugadas e desplugadas, ao ensino de Função, conteúdo matemático do currículo. Porém, na época da pesquisa, não foram identificadas propostas que contemplassem todos esses aspectos e, diante da necessidade de se levantarem trabalhos relacionados, optou-se por realizar duas revisões bibliográficas.

A primeira revisão associou o Pensamento Computacional à resolução de problemas matemáticos. As buscas foram realizadas no dia 29 de junho de 2019 e foi utilizado um recorte temporal para trabalhos publicados a partir de 2015. Já a segunda associou o ensino de Função ao uso de tecnologias digitais. As buscas foram feitas no dia 16 de dezembro de 2020 e o recorte temporal adotado foi para publicações a partir de 2017. Os recortes temporais foram adotados para se obterem trabalhos mais recentes e, na segunda revisão, considerando que buscas preliminares apresentaram um grande número de trabalhos, optou-se por diminuir o recorte a fim de tornar a seleção viável de ser realizada por apenas um pesquisador. As bases consultadas, nos dois casos, foram o Catálogo de Teses e Dissertações da Capes e o Google Acadêmico, tendo sido seguidos procedimentos sistematizados de busca e seleção.

O processo de seleção relacionado ao Pensamento Computacional, adotando critérios de inclusão e exclusão, resultou em três trabalhos relacionados: o artigo de Lopes et al. (2016) e as dissertações de Silva (2016) e de Mestre (2017). Os dois primeiros trabalhos foram experimentados na Educação Básica, propondo, respectivamente, o uso do Scratch e o do Code.org associado ao Scratch no desenvolvimento dos princípios do Pensamento Computacional, enquanto o terceiro propôs diretrizes metodológicas para adoção do Pensamento Computacional. Os três trabalhos abordaram conteúdos do currículo de Matemática.

O artigo de Lopes et al. (2016) apresentou, como um dos resultados, a melhoria na capacidade de resolução de problemas por parte dos alunos, enquanto Silva (2016) apontou a dificuldade dos alunos em resolverem problemas com várias informações. Apesar disso, a experiência mostrou uma evolução na criação e na execução de algoritmos. A pesquisa de Mestre (2017) permitiu o mapeamento de problemas matemáticos que podem auxiliar no desenvolvimento do Pensamento Computacional. Apesar de não ter sido experimentado com alunos, esse mapeamento foi validado por profissionais da área da computação. A partir dos três trabalhos, foi possível perceber que aspectos matemáticos e do Pensamento Computacional poderiam contribuir para alcançar o objetivo da pesquisa e quais deveriam ser evitados.

$\mathrm{Na}$ segunda revisão, aplicando-se critérios de inclusão e exclusão, também foram selecionados três trabalhos: o artigo de Bissi, Meneguelli e Sad (2017) e as dissertações de Carvalho (2017) e Silva (2017). Os três trabalhos fizeram uso do GeoGebra versão desktop para propor intervenções sobre o tema Função. O primeiro explorou, basicamente, as transformações que os coeficientes ocasionam na representação gráfica de uma função. O segundo utilizou recursos do GeoGebra, tais como tabelas, gráficos e escrita algébrica, trabalhando diferentes 
representações de uma função no programa. Já o terceiro trabalho explorou o tópico funções em investigações e na transposição de construção do software Imagiciel $^{6}$ para o GeoGebra.

Bissi, Meneguelli e Sad (2017) notaram uma compreensão efetiva sobre o conteúdo em foco, tanto pelos resultados da experimentação quanto por momentos posteriores a ela. Carvalho (2017) destacou a curiosidade e a facilidade que os alunos mostraram ao manipularem o GeoGebra, mesmo nunca o tendo feito antes, além de observar que a dificuldade dos estudantes em compreenderem o conceito de domínio é maior quando a análise é feita na representação gráfica da função. Por último, Silva (2017) destaca a dificuldade dos alunos em recobrar alguns conhecimentos prévios necessários para a resolução de determinadas situações propostas, mas, ainda assim, ocorreram aspectos positivos, tais como a compreensão das relações, a regularidade e a manipulação de applets $^{7}$ do GeoGebra. Os três trabalhos também trouxeram contribuições para a análise da abordagem de Função dada na pesquisa.

A partir do aporte teórico levantado, foi possível integrar o Pensamento Computacional à TAS na elaboração de uma proposta pedagógica voltada para o estudo de Função no Ensino Médio, conforme descrito na seção a seguir.

\section{Procedimentos metodológicos}

A pesquisa realizada teve caráter qualitativo, do tipo Intervenção Pedagógica. Para Gerhardt e Silveira (2009), a pesquisa qualitativa caracteriza-se, principalmente, pela preocupação com o aprofundamento da compreensão de características de determinado grupo social, em outras palavras, com os fatos da realidade que não podem ser quantificados, em detrimento de uma atenção com a representatividade numérica. Já a Intervenção Pedagógica é uma pesquisa da área educacional, na qual práticas de ensino diferenciadas são propositadamente elaboradas, executadas e avaliadas, tendo em vista promover melhorias nas práticas de sala de aula (DAMIANI et al., 2013). Assim, envolve o planejamento da proposta pedagógica, sua aplicação e a avaliação de seus efeitos (DAMIANI et al., 2013).

A Intervenção Pedagógica realizada ocorreu por meio de um Curso intitulado Estudo Introdutório de Função. A primeira autora deste trabalho mediou a intervenção, sob orientação das demais autoras, e contou com o apoio dos professores da disciplina de Matemática que lecionavam para o público-alvo, a saber: ingressantes na $1^{\mathrm{a}}$ série do Ensino Médio ${ }^{8}$, etapa em que há um aprofundamento no estudo de Funções.

$\mathrm{Na}$ fase de planejamento da Intervenção, elaboraram-se os seguintes instrumentos de coleta de dados: atividade de sondagem conceitual, questionários, inicial e final, atividade da terceira seção da apostila "Introdução de Função" e atividade final. Também foi adotada como instrumento de coleta a observação, cuja análise ocorreu segundo o aporte teórico adotado, assim como a dos questionários e da atividade da apostila. Já a atividade de sondagem e a atividade final foram analisadas com base na metodologia Análise de Erros (CURY, 2007).

\footnotetext{
${ }^{6}$ Segundo Silva (2017), o Imagiciel é “[...] um ambiente computacional desenvolvido por pesquisadores franceses na década de 1980 no ambiente DOS, voltado para o ensino de temas da Matemática acompanhado de caderno de atividades.".

7 Entende-se por applet um software que é desenvolvido em outro software. No caso de applets criados no GeoGebra, além de possibilitarem a construção dinâmica e a manipulação de vários entes matemáticos, não exigem conhecimento de linguagem de programação, podendo ser construídos pelo professor ou pelos próprios alunos.

${ }^{8}$ Por ter sido realizada com seres humanos, ressalta-se que a presente pesquisa, apresentada em recortes, foi submetida a um Comitê de Ética em Pesquisa (CEP) e aprovada, conforme CAAE 31436820.8.0000.5648.
} 
Destaca-se que o objetivo do questionário inicial foi identificar: i) o perfil do público-alvo no que diz respeito aos recursos tecnológicos que ele teria à disposição para participar do Curso; ii) se os alunos já tinham feito uso pedagógico de dispositivos móveis; iii) o perfil dos alunos quanto à Matemática; iv) se os alunos conheciam o aplicativo GeoGebra e que habilidades possuíam acerca dele.

A atividade de sondagem conceitual teve como objetivo identificar os subsunçores dos alunos acerca dos referidos conteúdos, estudados no final do Ensino Fundamental, assim como reconhecer suas dificuldades em resolução de problemas. Os conteúdos abordados foram representação de uma função em diagramas de setas e no plano cartesiano, construção gráfica, domínio, contradomínio e imagem, relações de dependência e independência entre duas variáveis, manipulações algébricas e resolução de problemas sobre o tema.

Além desses instrumentos de coleta, elaborou-se, também na fase de planejamento, a supracitada apostila. Composta por três seções, enfatizou, na primeira delas, o que são os princípios do Pensamento Computacional, abordando-os em uma situação-problema envolvendo operações básicas. Na segunda seção, desenvolveram-se a definição de função, a relação de dependência e independência entre duas variáveis, os conceitos de domínio, contradomínio e imagem, as representações gráficas de função por diagramas de setas e no plano cartesiano, a análise e a construção gráficas, além das estratégias para a resolução dos problemas propostos ao longo das discussões. Esses tópicos foram abordados à luz dos princípios do Pensamento Computacional, como se pode observar na Figura 1.

Figura 1 - Recorte da apostila "Introdução de Função"

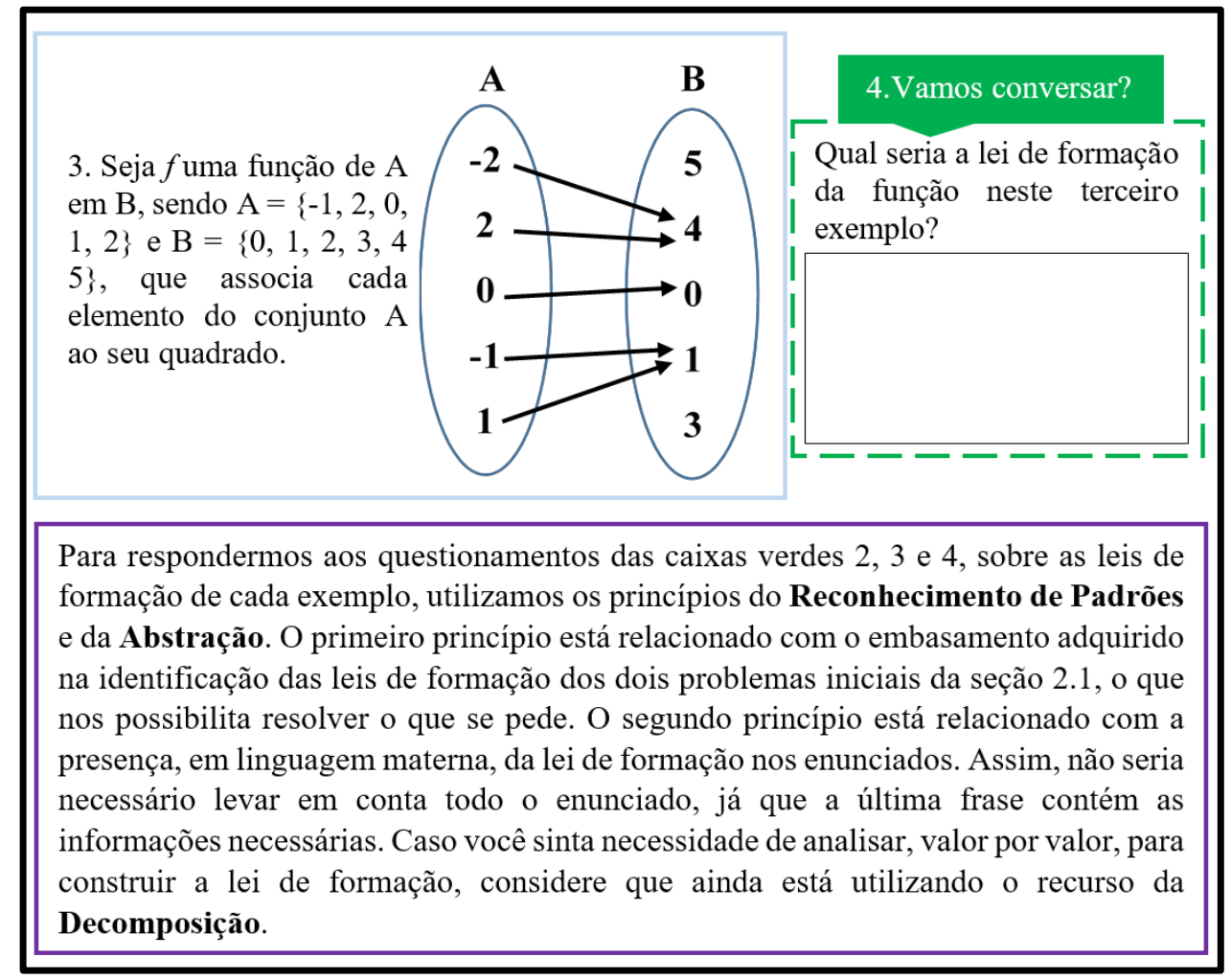

Fonte: Gomes (2021, p. 62).

A atividade da terceira seção da apostila e a atividade final tiveram como objetivo buscar por indícios de aprendizagem significativa dos conceitos abordados na apostila. Ambas foram 
compostas por problemas com nível de maior complexidade do que os trabalhados na atividade de sondagem conceitual e nas seções 1 e 2 da apostila. Por último, o questionário final teve como objetivo captar as percepções dos alunos sobre as atividades desenvolvidas, sobre o GeoGebra e sobre a forma de aplicação do Curso.

Realizou-se um teste exploratório dos questionários, das atividades e da apostila com cinco licenciandos. O objetivo do teste foi analisar esses materiais a fim de verificar: i) a adequação ao público-alvo; ii) a coerência do tempo planejado para experimentação; iii) a existência de erros conceituais no material que seria disponibilizado; iv) possíveis indicações de melhorias. De maneira geral, os materiais foram considerados adequados, sendo as sugestões mais significativas relativas à inserção de um tutorial de uso do aplicativo GeoGebra na apostila e à substituição de uma das questões da atividade final, considerando que o nível de dificuldade encontrava-se inadequado.

O Curso ocorreu durante o início das Atividades Pedagógicas Não-Presenciais ${ }^{9}$ (APNP) da Instituição Federal de Educação em que a primeira autora atua como técnica em assuntos educacionais. Cabe destacar que a presente proposta foi inicialmente elaborada para ser experimentada de forma presencial, porém o necessário isolamento social ocasionado pela pandemia de COVID-19 que atingiu o mundo impossibilitou que isso ocorresse. Assim o Curso foi realizado remotamente, por meio de encontros síncronos mediados por tecnologias digitais.

A inscrição dos alunos interessados ocorreu de 02/10/2020 a 05/10/2020 por meio do preenchimento de um formulário, criado no Google Formulários, cujo link foi divulgado, a partir do dia 02/10/2020. A divulgação foi feita pelos professores de Matemática responsáveis pela $1^{\mathrm{a}}$. série do Ensino Médio no ambiente virtual da disciplina e também durante o encontro síncrono da disciplina, que ocorreu no mesmo dia de abertura das inscrições, e contou com a presença de alunos dos quatro cursos de Ensino Médio Integrado da Instituição, Administração, Eletrotécnica, Informática e Química. Também foi divulgado pela primeira autora nos grupos de WhatsApp em que estavam os representantes das turmas.

Além da inscrição em si, o formulário também trazia as datas e os horários dos encontros do Curso, bem como descrevia quais recursos tecnológicos básicos os alunos precisariam ter para conseguirem participar dos sete encontros síncronos, como planejado inicialmente. Para definir o horário dos encontros, foi analisada a grade das disciplinas dos cursos integrados, a fim de que todos os interessados tivessem condições de participar. Assim, ficou definido para às $16 \mathrm{~h}$ com término às $17 \mathrm{~h} 30 \mathrm{~min}$.

Foram 57 inscritos interessados em realizar o Curso. Optou-se por realizar um sorteio, destinando-se seis vagas para cada curso integrado. Como dois alunos não eram ingressantes, o universo de inscritos tornou-se 55. Para o curso técnico em Administração, houve seis inscritos, não sendo necessário o sorteio. Já para os cursos técnicos em Eletrotécnica, Informática e Química houve, respectivamente, 27, 11 e 11 inscritos. Após os sorteios, realizouse contato, via WhatsApp individual, com cada aluno sorteado dentro do quantitativo de vagas de cada curso técnico integrado para verificar o real interesse e disponibilidade de recursos tecnológicos mínimos para participação. Todos os 24 sorteados, inicialmente, mostraram interesse e detinham os recursos, mas, antes do primeiro encontro, um aluno do curso de Administração desistiu de participar, por questões pessoais. Como não havia mais alunos inscritos desse curso, foram considerados 23 alunos.

\footnotetext{
${ }^{9}$ As APNP foram adotadas pela Instituição Federal de Educação em que a primeira autora experimentou seu produto educacional por conta da situação pandêmica vivida pelo mundo no ano de 2020. Consistem no retorno às aulas, de forma remota, ofertando disciplinas que comprovadamente pudessem ser adaptadas à realidade virtual.
} 
Para mediar a realização do Curso, foram utilizados os recursos do WhatsApp, do Google Meet ${ }^{10}$, do Google Classroom ${ }^{11}$ e do aplicativo Airdroid ${ }^{12}$. O WhatsApp foi usado no primeiro contato com os alunos inscritos e, após essa etapa, em um grupo para dar as orientações iniciais sobre o Google Classroom. O Google Meet permitiu a realização dos encontros com os alunos, enquanto o Google Classroom possibilitou a organização e o acesso dos alunos aos instrumentos de coleta de dados e à apostila, bem como para disponibilização dos links para postagem das respostas às atividades. Por último, o Airdroid foi utilizado para fazer o espelhamento de tela, nas ocasiões em que o aplicativo GeoGebra foi utilizado.

A partir dos procedimentos descritos nesta seção, foi realizada a fase de experimentação e de avaliação da Intervenção Pedagógica, conforme se apresenta na seção 4.

\section{Resultados e discussões}

Num momento inicial, os 23 alunos receberam informações gerais sobre o Curso e sobre a instalação do GeoGebra e também puderam tirar suas dúvidas. Os alunos já estavam familiarizados com o uso dos aplicativos Google Meet e Classroom. Credita-se esse fato ao seu grande uso como ferramentas para as atividades síncronas do Instituto em que o público-alvo estudava. Nesse mesmo encontro, foram respondidos o questionário inicial e a atividade de sondagem conceitual. Para fins de análise de dados, foram considerados apenas os alunos que participaram de todos os encontros, resolveram todas as atividades propostas, bem como responderam aos questionários. Assim, apresentam-se os resultados de oito alunos, denominados A1, A2, A3, ..., A8.

Por meio do questionário inicial, notou-se que todos os alunos possuíam recursos tecnológicos adequados à sua participação no Curso. Além disso, também foi possível identificar que sete alunos já haviam feito uso pedagógico de smartphone, dialogando com a constatação da UNESCO (2014) e de Resende e Müller (2018) de que o uso de dispositivos móveis em sala de aula já é uma realidade. Outro aspecto, identificado nesse questionário, foi que apenas A2 e A7 afirmaram não gostarem de Matemática e esses dois alunos, juntamente com A4, responderam que tinham dificuldade nessa disciplina, enquanto os demais alunos informaram não terem. Quanto ao conteúdo de Função, apenas A6 e A8 afirmaram não se recordar de tê-lo estudado. Nenhum dos alunos conhecia o GeoGebra.

A atividade de sondagem conceitual foi analisada segundo a metodologia Análise de Erros (CURY, 2007). Para tanto, salienta-se que foram consideradas 13 questões/itens (questão 1: itens 1.a e 1.b; questão 2; ..; questão 7: itens 7.a, 7.b, 7.c e 7.d), cujas respostas dadas, por cada aluno, foram unitarizadas em seis categorias: resposta correta (qualquer resposta ou resolução que apresentasse desenvolvimento considerado correto), sem resolução (qualquer questão ou item sem desenvolvimento), erro conceitual (resposta ou resolução que apresentasse erro na aplicação do(s) conceito(s) em foco, de forma correta), erro de interpretação (qualquer resposta ou resolução que apresentasse visão equivocada acerca dos dados do enunciado do problema), erro com operações básicas (qualquer resposta ou resolução que apresentasse erro de adição, subtração, multiplicação ou divisão) e erro na linguagem matemática formal

\footnotetext{
${ }^{10}$ Recurso que permite a realização de videochamadas. Neste trabalho foi utilizada a versão gratuita.

${ }^{11}$ Ambiente virtual de aprendizagem gratuito.

${ }^{12}$ Airdroid, segundo a página do aplicativo, disponível em https://www.airdroid.com/pt-br/get.html?init=personal, é um recurso de gerenciamento de dispositivos móveis, permitindo, entre outras ações, o espelhamento de tela.
} 


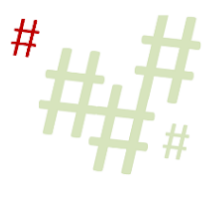

(qualquer resposta ou resolução que apresentasse representação em linguagem matemática equivocada).

Num contexto geral, $48,1 \%$ das respostas foram sem resolução, sendo que apenas A3 respondeu a todas as questões. Isso permitiu identificar que, mesmo aqueles alunos que afirmaram, no questionário inicial, recordarem-se de terem estudado Função, possuíam dificuldade em resolver questões sobre esse tema, fato que se relaciona à falta de uma aprendizagem significativa, conforme sugerido por Lima (2008). As principais dificuldades encontradas foram nos tópicos de domínio, abordado nas questões 1 e 6 , e de construção e análise gráfica, abordados, respectivamente, nas questões 3 e 2. Nesse sentido, discutem-se essas quatro questões.

No que diz respeito ao conjunto domínio de uma função, quatro alunos não responderam e apenas dois responderam de forma correta ao item 1.b, em que era pedido que identificassem esse conjunto em uma função representada em diagramas de setas. Além disso, na questão 6, em que havia um nível de complexidade maior que o item 1.b, apenas A3 soube descrever os conjuntos domínio de cada uma das funções propostas, analisando as suas restrições e descrevendo-as em linguagem algébrica. Dificuldades com esse conceito também foram identificadas por Alexandre e Santos (2009) e Justulin, Pereira e Ferreira (2019).

$\mathrm{Na}$ questão 3, item 3.c, em que os alunos deveriam fazer o esboço do gráfico de uma função polinomial do $1^{\circ}$. grau dada, três alunos esboçaram, sendo que apenas o gráfico de A5 foi considerado correto. De forma semelhante, houve dificuldades na questão 2, na qual os alunos deveriam analisar quatro representações no plano cartesiano e determinar qual delas representava uma função. Quatro alunos responderam e nenhum deles conseguiu identificar corretamente. É interessante destacar que A3 descreveu, em 1.a, uma definição correta de função, mesmo não tendo sido solicitado naquela questão, mas não conseguiu aplicar tal conceito para identificar corretamente o gráfico que representava uma função na questão 2, selecionando o gráfico equivocado. Credita-se esse fato a uma aprendizagem memorística da definição e do conceito de Função.

Diante da análise da atividade de sondagem conceitual, pôde-se perceber a necessidade de que, de fato, a apostila já construída partisse de conceitos do currículo de Matemática dos anos finais do Ensino Fundamental. Dessa forma, ela serviu tanto como um organizador prévio, conforme feito por Costa e Verdeaux (2016), visto a existência de poucos subsunçores relevantes à continuidade do estudo de Função, quanto possibilitou o aprofundamento do tema, com foco no desenvolvimento do Pensamento Computacional. Em particular, foi possível identificar a lacuna conceitual relacionada, principalmente, ao domínio, à construção e à análise gráfica, sendo necessária uma atenção especial a esses conceitos nos encontros.

No segundo encontro síncrono, foi dado início à apostila, com ênfase nos princípios do Pensamento Computacional na resolução de um problema. Sobre a Decomposição, os alunos reconheceram que trabalhar com problemas menores tornava mais fácil saber por onde começar, mesmo em problemas mais simples, como o que estava sendo resolvido naquele momento. Já em relação ao Reconhecimento de Padrões, todos os alunos concordaram que, de fato, torna-se mais simples ter respaldo em uma situação semelhante a uma que já vivenciaram.

O princípio da Abstração foi considerado o mais interessante para os alunos. Alguns comentários sinalizaram que, em geral, há a tendência de se usarem todas as informações disponibilizadas no enunciado de um problema, por serem consideradas, obrigatoriamente, necessárias. Assim, os participantes concordaram que a Abstração em muito auxilia na resolução de um problema. Quanto ao princípio do Algoritmo, notou-se que os alunos tiveram um pouco mais de dificuldade de entendê-lo, embora este seja, basicamente, o método, o passo 
a passo, o planejamento e a execução para se resolver o problema. Iniciaram-se, também, neste encontro, os conteúdos da segunda seção.

No decorrer do segundo encontro, notou-se pouca interação por parte dos alunos. Dessa forma, no início do terceiro encontro foi proposto um quis de modo a retomar alguns tópicos discutidos anteriormente e também para proporcionar uma dinâmica que poderia trazer motivação aos alunos, o que de fato ocorreu. Num contexto geral, destaca-se que do segundo ao sétimo encontro, foi desenvolvida a apostila com os participantes, sendo propostas discussões críticas sobre as atividades plugadas, que foram realizadas com o auxílio do GeoGebra. Também foram usados três applets desse aplicativo, no intuito de contribuir para a aprendizagem de conjunto domínio, contradomínio e imagem, em representações em diagramas de setas. Tanto durante as manipulações com os applets quanto nos momentos de plotagem de funções propostas na apostila, foram dadas orientações por meio do compartilhamento de tela.

Percebeu-se que situações-problemas que partiam de contextos reais dos alunos promoviam uma melhor compreensão do tópico em foco, como sugerido por Caraça (1951). Porém considerou-se ser também preciso, após o momento inicial, alcançar a superação dessa necessidade de associação ao real para que o aluno pudesse estabelecer novos significados para os conceitos trabalhados, tornando-o assim mais estável em sua estrutura cognitiva (MOREIRA, 2012).

Ressalta-se que, no momento de discussões acerca das restrições de domínio, foi necessário que se utilizasse um quadro branco, previamente instalado na parte posterior da bancada em que os equipamentos da primeira autora estavam dispostos. O mesmo ocorreu nos momentos de análises e construções gráficas. Notou-se que os alunos se sentiram à vontade para tirar suas dúvidas e também se observou que a linguagem para se referirem aos temas matemáticos trabalhados estava melhorando a cada discussão. No sexto encontro, visando-se a um melhor aproveitamento das atividades propostas, foi acordado com os alunos mais um encontro síncrono, totalizando então oito encontros. Dessa forma, a parte final da apostila poderia ser tratada com mais tranquilidade.

No sétimo encontro, deu-se início à atividade da terceira seção da apostila, composta por 13 questões/itens (questão 1; questão 2; questão 3: itens 3.a, 3.b, 3.c e 3.d; ..., questão 6: itens 6.a e 6.b). As respostas dadas pelos alunos foram analisadas segundo o aporte teórico adotado e são destacados alguns resultados relevantes. Ressalta-se que não foram feitas intervenções por parte da primeira pesquisadora durante a realização dessa atividade, assim como na atividade final, visto que o objetivo dessas atividades foi buscar por indícios de aprendizagem significativa dos conceitos abordados na apostila.

Na questão 1, notou-se uma melhoria no que diz respeito à construção gráfica, uma vez que se identificou a adoção de estratégias, por parte dos alunos, para fazer o esboço. Alguns deles não registraram qualquer cálculo para encontrar os pares ordenados que seriam marcados no plano cartesiano, mas, como a lei de formação e alguns pares ordenados referentes ao mesmo gráfico já haviam sido discutidos na apostila, considera-se que, motivados pelo princípio da Abstração, os alunos apenas recorreram a essas informações.

Ainda assim, é importante destacar que equívocos ocorridos na experimentação de Justulin, Pereira e Ferreira (2019) também foram cometidos por alguns alunos nessa construção: o domínio do gráfico era um conjunto discreto, mas quatro alunos ligaram os pontos, formando uma reta. Outro erro foi incluir o zero, que não fazia parte do conjunto domínio. Porém, num contexto geral, os resultados da questão 1 foram satisfatórios, já que todos os alunos buscaram a resolução, diferentemente do ocorrido na atividade de sondagem conceitual, em que apenas três alunos haviam tentado construir o gráfico pedido, tendo apenas um feito-o corretamente. 
Cabe ressaltar que o gráfico da referida questão 1 apresentava um grau de dificuldade maior do que aquele solicitado na atividade de sondagem.

A questão 2, uma atividade plugada, pedia que plotassem a lei de formação da função da questão 1 no GeoGebra, comparassem se o domínio representado no gráfico construído era, de fato, retratado na plotagem e, em caso negativo, em que as representações diferiam. Um dos alunos apenas reproduziu o gráfico construído anteriormente, mostrando um equívoco na interpretação do que a questão 2 pedia, três acertaram parcialmente em decorrência do erro cometido na construção do gráfico na questão 1, três erraram e apenas um aluno respondeu corretamente. As respostas apontaram que os alunos, assim como constatado por Silva (2016), têm dificuldade em resolver problemas cujo enunciado reúne muitas informações e, nesses casos, associa-se à falta do uso da Decomposição, princípio que poderia auxiliar na resolução dessa questão.

Já na questão 3, item 3.a, os alunos deveriam escrever a lei de formação de uma função que expressasse a situação real descrita no enunciado. Sete alunos responderam corretamente. Seis deles responderam apenas a partir da observação da relação entre as variáveis e A6 respondeu por meio de cálculos e manipulações algébricas. Cabe destacar que esse aluno, no questionário inicial, relatou que não se lembrava de ter estudado função, além de não ter feito nenhuma das questões da atividade de sondagem conceitual. Logo, a estratégia adotada por ele dá indícios de uma aprendizagem significativa dos conceitos que manipulou para resolver o problema. Salienta-se que A4 não respondeu corretamente a esse item, pois desconsiderou o valor inicial da lei de formação.

No item 3.b os alunos mostraram melhoria na capacidade de resolução de problemas ao escreverem um algoritmo para determinar a quantidade de água que ainda restaria em um reservatório, decorridos 15 minutos de esvaziamento, a 1 litro por minuto. Um aluno utilizou apenas linguagem materna ao escrever o algoritmo, três usaram linguagem materna associada à escrita matemática, dois fizeram uso apenas da escrita matemática e dois alunos erraram.

A questão 4 trouxe indicativos de que os alunos compreenderam como aplicar os princípios do Pensamento Computacional, pois necessitaram elaborar um problema que envolvesse uma função cujo domínio foi predeterminado como sendo o conjunto dos números naturais. Além disso, era necessário que fosse feita a representação tabular dessa função, a escrita da lei de formação referente à situação e a escrita de um algoritmo para determinar a imagem de um valor do domínio escolhido pelo aluno. Todos os alunos conseguiram fazer o que se pedia, usando diferentes ideias para tanto. Essa questão mostrou-se muito favorável ao desenvolvimento do Pensamento Computacional, conforme a definição de Wing (2017) adotada neste trabalho, visto que permite a criação e a resolução de um problema.

A questão 5, em que deveriam determinar se a reta de uma função polinomial do $1^{\circ}$. grau era crescente ou decrescente dados dois de seus pontos, também teve boa recepção por grande parte dos alunos. Dois alunos construíram a reta que passa pelos dois pontos dados, três utilizaram o conceito de crescimento e decrescimento de uma função polinomial do $1^{\circ}$. grau e dois fizeram o cálculo do coeficiente angular do gráfico para determinar a inclinação. Apenas um aluno não resolveu essa questão. As diversas formas de resolver a questão 5 mostraram apropriação de diferentes conceitos, tais como o crescimento e decrescimento, a representação gráfica de uma função decrescente e a caracterização da função decrescente pelo coeficiente angular negativo de sua reta.

Tais resoluções fornecem fortes indícios de uma aprendizagem significativa do conceito de crescimento e decrescimento de uma função polinomial do $1^{\circ}$. grau. Além disso, os alunos, ao mobilizarem diferentes conceitos para resolverem essa questão, também forneceram 
indicativos de que havia um processo de estabilização do conceito em foco. Na questão 6 da apostila, era preciso analisar, em 6.a, se o gráfico exibido representava uma função e também justificar, em 6.b, o motivo da resposta dada anteriormente. Cinco alunos conseguiram compreender e explicar o porquê de o gráfico apresentado não ser uma função, utilizando linguagem matemática adequada e até mesmo contraexemplos. Já nas respostas dos alunos que afirmaram tratar-se de uma função, observou-se a falta do uso dos princípios do Pensamento Computacional para adoção de uma estratégia ou mesmo alguma argumentação que respaldasse a ideia.

A atividade final, realizada no oitavo e último encontro, foi analisada segundo a metodologia Análise de Erros, os alunos puderam resolver outras 11 questões/itens (questão 1: itens 1.a e 1.b; questão 2: itens 2.a, 2.b e 2.c; ..., questão 5), cujas respostas dadas, por cada aluno, foram unitarizadas em seis categorias: resposta correta, erro conceitual, erro de interpretação, erro com operações básicas, erro na linguagem matemática formal e erro na manipulação do GeoGebra. Diferentemente do que ocorreu na realização da atividade de sondagem conceitual, a categoria sem resolução não teve ocorrência. São discutidas a seguir algumas das respostas. Como as cinco primeiras categorias foram adotadas da mesma forma como descrito anteriormente, na análise da atividade de sondagem conceitual, define-se, nesse momento, apenas o erro relacionado ao aplicativo: qualquer questão ou item que apresentasse o uso equivocado ou incorreto do GeoGebra.

De maneira geral, notou-se um aumento muito significativo no número de acertos das questões. Do total de respostas, $75 \%$ foram classificadas como corretas, enquanto $11,4 \%$ foram consideradas parcialmente corretas e apenas 13,6\% incorretas. Como na atividade de sondagem conceitual aproximadamente metade das questões não foram sequer respondidas, considerouse que trabalhar os princípios do Pensamento Computacional atrelados à ementa de Matemática proporcionou contribuições na capacidade de resolução de problemas, como também identificado por Lopes et al. (2016).

Notou-se, por meio das respostas da questão 1, que os alunos já conseguiam analisar relações representadas em diagramas de setas e determinar, em cada caso, qual era uma função. Além disso, souberam justificar corretamente o porquê de cada relação ser ou não ser uma função, mostrando compreensão do conceito. Fizeram uso da linguagem corrente, mas agregaram, na grande maioria, a linguagem matemática ao relacionarem dois conjuntos, A e B. No item 2.a, os alunos deveriam escrever a lei de formação da função que representava a situação-problema do enunciado da questão 2 , e, em sua maioria, não tiveram dificuldades. Já em 2.b, item no qual deveriam determinar os conjuntos domínio e imagem, houve dificuldade no entendimento de que o elemento zero pertencia ao conjunto domínio, além de algumas escritas matemáticas equivocadas das representações.

A questão 3, que era uma atividade plugada, foi considerada uma das mais complexas na atividade, mas, ainda assim, teve um bom aproveitamento por cinco alunos. Eles deveriam descrever uma função em que todas as imagens dos valores positivos de $x$ estivessem no quarto quadrante. Depois, deveriam generalizar, escrevendo a lei de formação da função, bem como as restrições para os coeficientes da reta que representa essa função de modo a sempre atender aos critérios do enunciado. As respostas dadas pelos alunos que não responderam corretamente indicam que tiveram dificuldade na interpretação do problema.

A questão 4, de maneira geral, obteve um bom feedback dos alunos, quanto às relações de dependência e independência entre duas variáveis, à lei de formação da função e também quanto ao algoritmo para se encontrar $f(11)$, conceitos pedidos nos itens 4.a, 4.b, 4.c e 4.d, respectivamente. 
A quinta e última questão exigia que os alunos fizessem uso de vários conceitos e também que planejassem, usando o aplicativo, uma forma de resolução para construir um polígono usando o gráfico de funções polinomiais do $1^{\circ}$. grau para fazer os lados. Diversas estratégias foram adotadas nas construções. A1, por exemplo, construiu um losango usando funções com coeficientes opostos e passando pelo mesmo ponto no eixo $y$ e também no eixo $x$. Com isso, se tornou mais fácil delimitar o domínio para que os gráficos formassem um polígono.

A2, por sua vez, determinou, de forma mais clara, as etapas de construção de um triângulo. Observou-se que o aluno não apresentou cálculos por meio dos quais teria encontrado os pontos de interseção entre os gráficos que representam as funções, que chamou de $f(x), g(x)$ e $h(x)$. Ressalta-se, ainda, que o esboço do aluno não permitiria identificar, com exatidão, quais seriam os pontos de interseção. Dessa forma, a resposta dada sugere que ele recorreu ao GeoGebra para encontrar as interseções. As duas construções permitiram identificar indícios de aprendizagem significativa. A primeira construção indica que o aluno conseguiu assimilar, analiticamente, a disposição das retas no plano cartesiano a partir dos conhecimentos relativos aos seus coeficientes. Na segunda construção, o aluno poderia ter escolhido quaisquer outras funções, aleatoriamente, porém escolheu duas funções das quais já conhecia o ponto de interseção e, muito provavelmente, utilizou o GeoGebra para definir os outros dois pontos de interseção.

Mesmo aqueles que não conseguiram resolver completamente o problema, adotaram estratégias interessantes, a exemplo de A4, que iniciou a construção pela marcação de três pontos no plano cartesiano. A ideia de partir de três pontos predefinidos foi excelente, pois bastaria traçar as retas que passavam por eles, dois a dois, e definir a lei de formação de cada uma para que pudesse plotar no programa e delimitar o domínio. Porém, observou-se que o aluno não conseguiu analisar dessa forma e nem de outra, mesmo utilizando o GeoGebra.

A5 e A6 plotaram, no GeoGebra, funções constantes para construir, respectivamente, um trapézio e um triângulo isósceles. Apesar de o enunciado solicitar explicitamente que fossem usados gráficos de funções polinomiais de $1^{\circ}$ grau, consideraram-se as resoluções corretas, em razão da capacidade de resolução do problema e em como os dois alunos associaram conceitos no aplicativo para construir os polígonos.

De maneira geral, identificaram-se, na atividade final, alguns erros cometidos pelos alunos. Porém, a partir de uma leitura ampla desta atividade, julgou-se que são erros construtivos de um grupo que, majoritariamente, conhecia muito pouco sobre Função, tinha muitas dificuldades em resolução de problemas matemáticos e detinha poucos subsunçores apropriados à aprendizagem significativa desse tema. Alguns alunos apresentaram dificuldades na manipulação do GeoGebra para a realização das questões 3 e 5 e associa-se esse fato com a pouca exploração do aplicativo, já que, nas propostas da apostila que exigiam o seu uso, apenas alguns alunos interagiram. Ponderou-se que o espelhamento de tela do GeoGebra, feito nos encontros pode ter contribuído para as dificuldades apresentadas, pois considerou-se que levou a certo comodismo por parte dos alunos.

Apesar dos erros, foi possível perceber uma melhoria na capacidade dos alunos em resolver problemas, como também houve indícios de aprendizagem significativa, notados na análise dos problemas propostos. De fato, as respostas dadas ao questionário final corroboram a ideia de que a proposta pedagógica contribuiu para o estudo de Função, uma vez que todos os alunos, numa escala de 1 a 5, sendo 1 e 5, respectivamente, equivalentes a discordo e a concordo, concordaram que propor situações-problemas foi motivador para aprendizagem dos temas abordados. Também foram unânimes quanto ao fato de que estruturar as resoluções dos 
problemas seguindo os quatro princípios apresentados facilitou entender e resolver os problemas.

Além disso, sete alunos concordaram que resgatar conhecimentos anteriores auxiliou na resolução dos problemas e A4 concordou parcialmente (posição 4 na escala). Essas mesmas respostas foram dadas quando foi questionado se as atividades propostas facilitaram a compreensão do conteúdo de Função. Salienta-se, ainda, que todos responderam que gostariam de estudar outros conteúdos de Matemática da forma como o estudo de Função foi proposto. Quanto ao GeoGebra, destacam-se duas ponderações relevantes sobre o uso do aplicativo por parte dos alunos. Primeiramente, alguns deles citaram que foi difícil aprender a usar o GeoGebra ao mesmo tempo em que eram discutidos os tópicos da apostila. A segunda ponderação diz respeito à utilização dos recursos do GeoGebra no auxílio à compreensão do conceito de Função, o que os alunos entenderam ter sido positivo, assim como no trabalho de Bissi, Meneguelli e Sad (2017).

Todos os alunos teceram considerações sobre os aspectos positivos do Curso. Destacase que alguns deles citaram que as atividades ajudaram tanto a recordar os tópicos de Função como a somar novos conhecimentos, reforçando a ideia de que a apostila serviu como um organizador prévio, em alguns momentos, tanto quanto oportunizou o aprofundamento na temática. Nenhum dos alunos citou algum ponto negativo sobre o Curso em si. Um aluno citou problemas pessoais e outro relatou alguns problemas com sua conexão à internet, durante alguns encontros.

\section{Considerações finais}

Diante da proposta da BNCC (BRASIL, 2018) de implementação do Pensamento Computacional junto ao currículo da Educação Básica e das dificuldades que os alunos do Ensino Médio apresentam na compreensão do conceito de Função, buscou-se desenvolver uma pesquisa qualitativa para atender ao seguinte objetivo: investigar como uma proposta pedagógica baseada nos princípios do Pensamento Computacional e na TAS pode contribuir para o estudo de Função no Ensino Médio.

Para alcançá-lo, elaborou-se uma proposta pedagógica que integrou as duas teorias e foi experimentada com alunos ingressantes no Ensino Médio. Identificou-se que, apesar de a maioria dos alunos ter respondido, no questionário inicial, que já havia estudado o conteúdo, apenas um aluno considerou ter, de fato, compreendido o conceito de Função. Foi perceptível que os alunos não tiveram uma aprendizagem significativa do tema e também que possuíam poucos subsunçores adequados para sua construção. Nesse sentido, a proposta pedagógica apresentou-se adequada às necessidades do público-alvo, pois tanto desenvolveu conceitos de Função, atrelados aos princípios do Pensamento Computacional, como também se delineou como um organizador prévio, contribuindo para resgatar conhecimentos prévios esquecidos ou construindo novos.

Foram vivenciados desafios derivados da experimentação de forma remota, principalmente a pouca interação e o cansaço dos alunos em alguns encontros. Ainda assim, o estudo mostrou que a proposta pode ser implementada no Ensino Médio e que trouxe contribuições efetivas para a aprendizagem significativa de Função, como mostraram os resultados.

A análise dos dados coletados permitiu identificar indícios de aprendizagem significativa nas respostas dadas pelos alunos às atividades aplicadas após a proposta. Além disso, importa dizer que os alunos conseguiram resolver problemas de maior complexidade se 
comparados aos propostos antes da atividade da seção 3 da apostila e da atividade final. Nesses problemas, os alunos precisaram relacionar conceitos trabalhados ao longo do Curso e atribuir novos significados a eles. Destaca-se também que, até mesmo nos erros cometidos na atividade da terceira seção da apostila e na atividade final, pôde-se perceber a adoção de estratégias que não foram identificadas na atividade de sondagem conceitual. Ressalta-se ainda que a manipulação do GeoGebra para resolução dos problemas, mesmo que tenha representado uma dificuldade para alguns cursistas, mostrou ser uma forma interessante para o uso do aplicativo.

Cabe destacar que a proposta pedagógica, elaborada e experimentada, constituiu o produto educacional oriundo da pesquisa, sendo um dos requisitos para obtenção do título de mestre na área de Ensino. Esse produto pode ser encontrado na EduCAPES ${ }^{13}$. Como sugestão para trabalhos que tenham como objetivo aplicar os princípios do Pensamento Computacional como feito na pesquisa da qual este trabalho deriva, sugere-se que o docente ou pesquisador se aproprie dos princípios e analise o tema que deseja desenvolver com os alunos, buscando por tópicos que possam ser abordados dessa forma.

Vale observar que não é necessário, e nem sempre possível, abordar os quatro princípios em todos os tópicos. Quanto às experimentações remotas que utilizem o aplicativo GeoGebra ou semelhante, sugere-se que todas as atividades relacionadas sejam feitas de forma síncrona e, também, que seja solicitado aos alunos a captura de tela de seus smartphones, a fim de acompanhar o progresso de cada um e também se inteirar melhor das dificuldades. Em caso de experimentação de forma presencial, é sugerido atenção nas questões que necessitam do uso do GeoGebra, no sentido de orientar atentamente os alunos e também possibilitar um espaço de troca entre professor-aluno e aluno-aluno, o que foi dificultado no Curso online extracurricular.

Para trabalhos futuros, sugerem-se propostas que deem continuidade ao estudo de Função, trabalhando, por exemplo, funções quadráticas ou funções exponenciais e também se sugerem pesquisas que abordem outros conteúdos matemáticos. Espera-se, de maneira geral, que o produto educacional elaborado possa despertar o interesse de professores e pesquisadores em implementar o Pensamento Computacional como proposto na BNCC (BRASIL, 2018).

\section{Referências}

ALEXANDRE, P. P.; SANTOS, M. H. S. M. Principais dificuldades de alunos do $2^{\circ}$ ano do ensino médio quanto a interpretação gráfica da função quadrática. In: SIMPÓSIO NACIONAL DE ENSINO DE CIÊNCIAS E TECNOLOGIA, 1., Ponta Grossa, 2009. Anais [...]. Ponta Grossa: UTFPR, 2009. Disponível em:

http://www.sinect.com.br/anais2009/artigos/10\%20Ensinodematematica/Ensinodematematica _artigo21.pdf. Acesso em: 30 dez. 2020.

ALMEIDA, C. M. M.; COSTA, R. D. A.; LOPES, P. T. C. Análise do desempenho acadêmico e da aprendizagem significativa no ensino superior utilizando as tecnologias digitais. Nuances, v. 28, n. 1, p. 25-43, jan./abr. 2017. Disponível em:

https://revista.fct.unesp.br/index.php/Nuances/article/view/4836/pdf_1. Acesso em: 10 mar. 2021.

ALMEIDA, M. E. B. de; VALENTE, J. A. Pensamento computacional nas políticas e práticas em alguns países. Revista Observatório, Palmas, v. 5, n. 1, p. 202-242, jan./mar. 2019.

${ }^{13}$ Disponível em: http://educapes.capes.gov.br/handle/capes/597245. 
Disponível em:

https://sistemas.uft.edu.br/periodicos/index.php/observatorio/article/view/4742/14697. Acesso em: 11 abr. 2019.

AUSUBEL, D. P. Aquisição e retenção de conhecimentos: uma perspectiva cognitiva. Lisboa: Plátano Edições Técnicas. 2003.

BARDIN, L. Análise de Conteúdo. Lisboa, Portugal: Edições 70, 1977.

BRACKMANN, C. P. Desenvolvimento do pensamento computacional através de atividades desplugadas na educação básica. 2017. 226 f. Tese (Doutorado em Informática na Educação) - Universidade Federal do Rio Grande do Sul, Porto Alegre, 2017.

BRASIL. Base Nacional Comum Curricular: educação é a base. Brasília: Ministério da Educação, 2018. Disponível em:

http://basenacionalcomum.mec.gov.br/images/BNCC_EI_EF_110518_versaofinal_site.pdf. Acesso em: 11 abr. 2019.

BISSI, T.; MENEGUELLI, L.; SAD, L. A. Utilizando o GeoGebra para o ensino de função polinomial do primeiro grau. Revista Eletrônica Sala de Aula em Foco, v. 6, n. 1, p. 85-95, 2017.

CARAÇA, B. J. Conceitos Fundamentais da Matemática. Lisboa: Tipografia Matemática, 1951.

CARVALHO, L. P. Um estudo das concepções de estudantes do ensino médio sobre o conceito de função com base na teoria de registros de representações semióticas. 2017. 152 f. Dissertação (Mestrado em Educação em Ciências e Matemática) - Universidade Federal de Pernambuco, Caruaru, 2017.

CONFORTO, D. et al. Pensamento computacional na educação básica: interface tecnológica na construção de competências do século XXI. Revista Brasileira de Ensino de Ciências e Matemática, Passo Fundo, v. 1, n. 1, p. 99-112, jan./jun. 2018.

COSTA. E. J. F. Pensamento Computacional na Educação Básica: uma abordagem para estimular a capacidade de resolução de problemas na Matemática. 2017. 157 f. Dissertação (Mestrado em Ciências da Computação) - Universidade Federal de Campina Grande. 2017.

COSTA, T. M.; VERDEAUX, M. F. S. Gamificação de materiais didáticos: uma proposta para a aprendizagem significativa da modelagem de problemas físicos. Experiências em Ensino de Ciências, v. 11, n. 2, p. 60-105, 2016. Disponível em: https://if.ufmt.br/eenci/artigos/Artigo_ID311/v11_n2_a2016.pdf. Acesso em: 08 mar. 2021.

CRUZ, J. M. F. Funções de duas variáveis, representação gráfica e integração. Revista do Instituto GeoGebra Internacional de São Paulo, v. 8, n. 1, p. 47-70, 2019. Disponível em: https://revistas.pucsp.br/IGISP/article/view/37352/29036. Acesso em: 30 jun. 2019.

CURSINO, A. G. Contribuições das tecnologias para uma aprendizagem significativa e o desenvolvimento de projetos no Ensino Fundamental I. 2017. 141 f. Dissertação

(Mestrado Profissional em Projetos Educacionais de Ciências) - Universidade de São Paulo. Lorena, 2017. 
CURY, H. N.; CASSOL, M. Análise de erros em cálculo: uma pesquisa para embasar mudanças. Acta Scientiae, v. 6, n. 1, p. 27-36, jan./jun. 2004. Disponível em: http://www.periodicos.ulbra.br/index.php/acta/article/viewFile/128/116. Acesso em: 29 jun. 2019.

CURY, H. N. Análise de Erros: o que podemos aprender com as respostas dos alunos. Belo Horizonte: Autêntica, 2007.

DAMIANI, M. F. et al. Discutindo pesquisas do tipo intervenção pedagógica. Cadernos de Educação, Pelotas, n. 45, p. 57-67, maio/ago. 2013. Disponível em:

https://periodicos.ufpel.edu.br/ojs2/index.php/caduc/article/view/3822/3074. Acesso em: 08 mar. 2019.

DOMINGUES, M. A. F. G.; STURION, L.; CARVALHO, A. A. A. Investigando função composta com o software GeoGebra. Revista Ensino de Ciências e Matemática, v. 10, n. 3, p. 132-147, 2019. Disponível em:

http://revistapos.cruzeirodosul.edu.br/index.php/rencima/article/view/1985/1134. Acesso em: 30 jun. 2019.

EVES, H. Introdução à história da Matemática. 5. ed. Campinas: Unicamp, 2011. Disponível em:

https://ia803005.us.archive.org/32/items/HistriaDaMatemtica/Hist\%C3\%B3ria\%20da\%20Ma tem\%C3\%A1tica.pdf. Acesso em: 10 mar. 2021.

GERHARDT, T. E.; SILVEIRA, D. T. Métodos de pesquisa. Porto Alegre: UFRGS, 2009. Disponível em: http://www.ufrgs.br/cursopgdr/downloadsSerie/derad005.pdf. Acesso em: 12 abr. 2019.

GOMES, L. L. Estudo de Função no Ensino Médio: uma proposta pedagógica baseada no Pensamento Computacional. 2021. 205 f. Dissertação (Mestrado Profissional em Ensino e suas Tecnologias) - Instituto Federal Fluminense, Campos dos Goytacazes, 2021.

JUSTULIN, A. M.; PEREIRA, F. F.; FERREIRA, A. S. Representação gráfica de funções: uma análise das principais dificuldades de alunos do Ensino Médio. REnCiMa, v. 10, n. 6, p. 301-318, 2019. Disponível em:

http://revistapos.cruzeirodosul.edu.br/index.php/rencima/article/view/1313/1207. Acesso em: 30 dez. 2020.

LEMOS, P. G. A. Funções aplicadas a Física a Química. 2013. 82 f. Dissertação (Mestrado Profissional em Matemática em Rede Nacional) - Universidade Federal de Juiz de Fora, Juiz de Fora, 2013.

LIMA, L. Aprendizagem significativa do conceito de função na formação inicial do professor de Matemática. 2008. 319 f. Dissertação (Mestrado Acadêmico em Educação) Universidade Estadual do Ceará, Fortaleza, 2008.

LOPES, C. C. et al. O Ensino de Algoritmos e Lógica de Programação como uma Ferramenta Pedagógica para Auxiliar a Aprendizagem de Matemática: Um Relato de Experiência. In: WORKSHOP DE INFORMÁTICA NA ESCOLA, 12., 2016, Uberlândia. Anais [...]. Uberlândia: Universidade Federal Uberlândia, 2016. Disponível em: http://www.brie.org/pub/index.php/wie/article/view/6601/4512. Acesso em: 29 jul. 2019. 
LOPES, W. S. A Importância da Utilização de Múltiplas Representações no

Desenvolvimento do Conceito de Função: uma Proposta de Ensino. 2003. 106 f. Dissertação (Mestrado em Educação Matemática) - PUC/SP, São Paulo, 2003.

MESTRE, P. A. O uso do Pensamento Computacional como estratégia para Resolução de Problemas Matemáticos. 2017. 103 f. Dissertação (Mestrado em Ciências da Computação) Universidade Federal de Campina Grande, Campina Grande, 2017.

MOREIRA, M. A. O que é afinal Aprendizagem Significativa?. Qurriculum, La Laguna, Espanha, p. 1-27, 2012. Disponível em: http://moreira.if.ufrgs.br/oqueeafinal.pdf. Acesso em: 19 maio 2019.

NASSER, L.; SOUSA, G. A.; TORRACA, M. A. Transição do Ensino Médio para o Superior: como minimizar as dificuldades em cálculo? In: SEMINÁRIO INTERNACIONAL DE PESQUISA EM EDUCAÇÃO MATEMÁTICA, 5., 2012, Petrópolis. Anais [...]. Petrópolis: Hotel Vale Real, 2012. Disponível em: http://www.sbembrasil.org.br/files/v_sipem/PDFs/GT04/CC18595006768_A.pdf. Acesso em: 29 jun. 2019.

PAPERT, S. Artificial Intelligence LOGO: Teaching Children Thinking. Logo Memo, n. 2, p. 1-19, 1971. Disponível em: https://archive.org/stream/bitsavers_mitaiaimAI_471587/AIM247_djvu.txt. Acesso em: 28 jul. 2019.

RESENDE, B.; MÜLLER, T. J. Mobile-learning: aprendizagem matemática por meio de realidade aumentada. Tear: Revista de Educação, Ciência e Tecnologia, Canoas, v. 7, n. 2, p. 1-14, 2018. Disponível em: https://periodicos.ifrs.edu.br/index.php/tear/article/view/3187. Acesso em: 15 jun. 2021.

SANTOS, G. L. D.; BARBOSA, J. C. Um modelo teórico de Matemática para o ensino do conceito de função a partir de um estudo com os professores. Revista Iberoamericana de Educação Matemática, n.18, p. 143-167, dez. 2016. Disponível em:

http://www.fisem.org/www/union/revistas/2016/48/175-744-1-ED_corrigido.pdf. Acesso em: 26 ago. 2019.

SILVA, H. N. Estudo de Função: uma proposta de reconstrução de atividades do Imagiciel mediadas pelo GeoGebra. 2017. 175 f. Dissertação (Mestrado em Educação Matemática) Pontifícia Universidade Católica de São Paulo, São Paulo, 2017.

SILVA, S. P. da. O uso da lógica de programação para a Educação Matemática no Ensino Médio: experiências com o Scratch. 2016. 135 f. Dissertação (Mestrado em Ensino de Ciências e Matemática) - Universidade Federal de Pelotas, Pelotas, 2016.

SOUSA, M. C.; MOURA, M. O. Estudo das historiografias de Paul Karlson, Konstantin Ríbnikov, Howard Eves e Bento de Jesus Caraça: diferentes modos de ver e conceber o conceito de função. Ciência e Educação, Bauru, v. 25, n. 4, p. 1081-1099, 2019. Disponível em: https://www.scielo.br/pdf/ciedu/v25n4/1516-7313-ciedu-25-04-1081.pdf. Acesso em: 30 dez. 2020.

UNESCO. O futuro da aprendizagem móvel: implicações para planejadores e gestores de políticas. Brasília: UNESCO, 2014. Disponível em: https://unesdoc.unesco.org/ark:/48223/pf0000228074. Acesso em: 9 jun. 2019. 
VALENTE, J. A. Integração do pensamento computacional no currículo da educação básica: diferentes estratégias usadas e questões de formação de professores e avaliação do aluno. Revista e-Curriculum, São Paulo, v.14, n. 3, p. 864-897, jul./set. 2016. Disponível em: https://revistas.pucsp.br/curriculum/article/view/29051/20655. Acesso em: 11 abr. 2019.

WING, J. M. Computational Thinking. Communications of the ACM, v. 49, p. 33-35, n. 3, mar. 2006. Disponível em: https://www.cs.cmu.edu/ ./15110-s13/Wing06-ct.pdf. Acesso em: 11 abr. 2019.

WING, J. M. Computational thinking's influence on research and education for all. Italian Journal of Educacional Technology, v. 25, n. 2, p. 7-14, 2017. Disponível em: http://www.cs.cmu.edu/ wing/publications/Wing17.pdf. Acesso em: 11 abr. 2019.

Recebido em agosto de 2021.

Aprovado em outubro de 2021. 